\title{
Statistical Analysis of the Quantified Relationship between Evaporation Duct and Oceanic Evaporation for Unstable Conditions
}

\author{
Qi ZHANG, KUNDE YANG, AND QIULONG YANG \\ School of Marine Science and Technology, Northwestern Polytechnical University, and Key Laboratory of Ocean Acoustics and \\ Sensing (Northwestern Polytechnical University), Ministry of Industry and Information Technology, Xi'an, China
}

(Manuscript received 10 September 2017, in final form 8 October 2017)

\begin{abstract}
An analysis is conducted for the first time to statistically quantify the relationship between the evaporation duct and oceanic evaporation. Through sensitivity analysis, under unstable conditions (air-sea temperature difference less than zero), evaporation duct and evaporation are found to maintain a similar trend with variations in air-sea variables, indicating a possible inherent connection. Furthermore, scatterplots of relevant historical data reveal that the evaporation duct generally increases in a power-law manner with evaporation. Therefore, logarithmic transformation is performed on the data, and then linear regression is adopted to derive the analytical expression of the linear trend. Additionally, based on this analytical expression, a three-parameter empirical model is proposed to estimate the temporal clustering, and the estimated result shows good agreement with the real distribution. The spatial variations of the parameters modeled over different focus areas reflect the influence of geophysical parameters.
\end{abstract}

\section{Introduction}

In marine environments, rapid decay of moisture at the bottom of the marine atmospheric boundary layer (MABL) can result in a large change to the vertical gradient in humidity (Saeger et al. 2015; Wagner et al. 2016). If the gradient extends sufficiently high (always within a few tens of meters), an anomalous atmospheric structure forms in which the propagation of electromagnetic waves is similar as when trapped in a waveguide. This kind of structure is known as the evaporation duct, and the relevant anomalous effectknown as ducting - can significantly affect radio systems, especially those working at the microwave band (Brooks 2001; Shi et al. 2015a,b; Lentini and Hackett 2015; Zhang et al. 2016b; Fountoulakis and Earls 2016; Kang and Wang 2016).

Refraction, the cause of this ducting phenomenon, can be characterized by the vertical gradients of the air refractive index $n$ (Yardim et al. 2006; Fountoulakis and Earls 2016). Since $n$ is close to unity ( 1.000350), the amplified difference of the refractive index from unity by a factor of $10^{6}$, known as refractivity $N$, is adopted. Additionally, to account for the curvature of

Corresponding author: Kunde Yang, ykdzym@nwpu.edu.cn
Earth, $N$ is usually replaced with modified refractivity $M$, which is related to air temperature $T(\mathrm{~K})$, total atmospheric pressure $P(\mathrm{hPa})$, partial pressure of water vapor $e(\mathrm{hPa})$, and the height above sea surface $z(\mathrm{~m})$ through the following formula (Bean and Dutton 1966; Yang et al. 2009):

$$
M=\frac{77.6 P}{T}-5.6 \frac{e}{T}+3.75 \times 10^{5} \frac{e}{T^{2}}+0.157 z .
$$

The difference in height between the top of the trapping layer, where $M$ reaches a minimum, and the sea surface is defined as the evaporation duct height $(\mathrm{EDH})$, which is the most widely-used parameter to quantify the ducting effect. Therefore, we also use the EDH to represent the evaporation duct in our analysis. To determine the EDH, the $M$ profile is needed, which, as shown in Eq. (1), can be calculated from the profiles of temperature and pressure. To derive these profiles, the Monin-Obukhov similarity theory and the Liu-Katsaros-Businger theory are employed, combined with meteorological parameters [air temperature $(2 \mathrm{~m})$, sea surface temperature (SST), relative humidity $(2 \mathrm{~m})$, wind speed $(10 \mathrm{~m})$, and sea level pressure] (Babin and Dockery 2002; Frederickson et al. 2000). For brevity, the computational procedures for the $\mathrm{EDH}$ are omitted here; for more details, please refer to 
our previous works (Yang et al. 2009; Shi et al. 2015c; Zhang et al. 2016a; Yang et al. 2016). A detailed flowchart of the procedures can be found in Yang et al. (2017b).

The formation of an evaporation duct primarily takes place in conjunction with a hydrolapse (Turton et al. 1988). The major meteorological process associated with a hydrolapse is oceanic evaporation (Lentini 2015), which is a complex dynamic process affected by many ocean environmental factors. Because of a lack of direct observations, the bulk relation derived from bulk parameterization and similarity theory is adopted to estimate evaporation from marine-atmospheric factors as follows (Liu et al. 1979; Yu and Weller 2007; Yu et al. 2008; Yu 2007; Su et al. 2015):

$$
\begin{aligned}
H_{l} & =\rho_{a} L_{e} C_{e}\left(U_{a}-U_{s}\right)\left(q_{s}-q_{a}\right), \\
E & =\mathrm{LHF} / \rho_{w} L_{e},
\end{aligned}
$$

where $H_{l}$ represents the latent heat flux, $E$ stands for the rate of evaporation, and $\rho_{a}$ is the density of surface air $\left(1.2 \mathrm{~kg} \mathrm{~m}^{-3}\right)$. The parameter $\rho_{w}$ is the density of seawater $\left(1027 \mathrm{~kg} \mathrm{~m}^{-3}\right), C_{e}$ represents the drag transport coefficients of moisture, and $L_{e}$ is the latent heat of vaporization, which can be expressed as $L_{e}=[2.501-(0.00237 \times \mathrm{SST})] \times 10^{6}$. The term $U_{a}$ is the near-surface wind speed, typically at the height of $10 \mathrm{~m}$, and $U_{s}$ is the ocean surface current speed, which is much smaller than $U_{a}$ and is assumed to be 0 . The sea surface saturation specific humidity is represented by $q_{s}$, and $q_{a}$ is the near-surface atmospheric specific humidity. The role of ocean surface waves in evaporative processes is neglected in this study. ${ }^{1}$

Water vapor diffusing from sea surface to a certain height leads to a sharp decay in moisture with height. This helps to sustain a vertical gradient of air-sea moisture fluxes. Obviously, to a certain extent, the evaporation duct is closely related to evaporation, hence the name "evaporation duct." This has been confirmed by our recent research (Yang et al. 2017a), which qualitatively reveals the strong coherent relevance between them. However, the relationship between the evaporation duct and evaporation, in a quantitative sense, remains somewhat underexplored. In this study, we aim to address this gap by presenting an estimate and a model of the relationship.

\section{Sensitivity analysis}

The evaporation duct is primarily affected by four environmental factors: near-surface wind speed, air

\footnotetext{
${ }^{1}$ Because of the limitation of length, more technical support about the computation of EDH and evaporation could be obtained via e-mail from the authors.
}

temperature, SST, and relative humidity (Ramsaur 2009; McKeon 2013). The response of the EDH to variations in these factors is dependent on the thermodynamic atmospheric state, which is characterized by the air-sea temperature difference (ASTD) (Zhang et al. 2016a). Positive, zero, and negative values of ASTD $\left({ }^{\circ} \mathrm{C}\right)$ roughly correspond to stable, neutral, and unstable conditions, respectively.

From bulk formulas [Eqs. (2) and (3)], evaporation depends directly on the SST and air-sea specific humidity difference. The drag transport coefficients of moisture are mainly determined by the atmospheric stability in terms of air-sea temperature differences (Fairall et al. 1996, 2003). Zveryaev and Hannachi (2012) analyzed the sensitivity of evaporation to changes in the surface winds, SST, and ASTD, and concluded that the correlation between evaporation and the ASTD is much stronger than that with SST. This inspired us to also use the ASTD as an independent variable to analyze the variations of evaporation.

Consequently, we conduct a sensitivity analysis of the EDH and evaporation versus ASTD for various values of relative humidity $(60 \%-90 \%)$, SST $\left(15^{\circ}-30^{\circ} \mathrm{C}\right)$, and wind speed (1-10 $\left.\mathrm{m} \mathrm{s}^{-1}\right)$. From Fig. 1, we can see that the difference in behavior between EDH and evaporation for positive and negative values of the ASTD is significant. When the ASTD is negative, the evaporation duct and evaporation maintain a similar relative trend in response to the variations in relative humidity, SST, and wind speed. A higher EDH and larger evaporation are associated with lower relative humidity (Figs. 1a and 1b), higher SST (Figs. 1c and 1d), and stronger surface wind (Figs. 1e and 1f). The differences lie in the different general trends with respect to the ASTD. This suggests that the correlation between the evaporation duct and evaporation may not be linear. When the ASTD is positive, evaporation maintains the same trend as under unstable conditions. However, for the evaporation duct the response is less straightforward. We can conclude that under unstable conditions (ASTD $<0^{\circ} \mathrm{C}$ ), there is a clear strong correlation between the evaporation duct and evaporation, but the relationship for a stable condition is rather complex and vague. Hence, we consider only the unstable condition in the following discussion.

\section{Statistical analysis of the relationship}

Both evaporation ducts and evaporation are involved in the complex process of air-sea interaction. However, at present, there is no physical model to quantify the relationship from a particular set of parameters. Therefore, a statistical method that relies on empirical analyses of historical data is adopted in our analysis. 

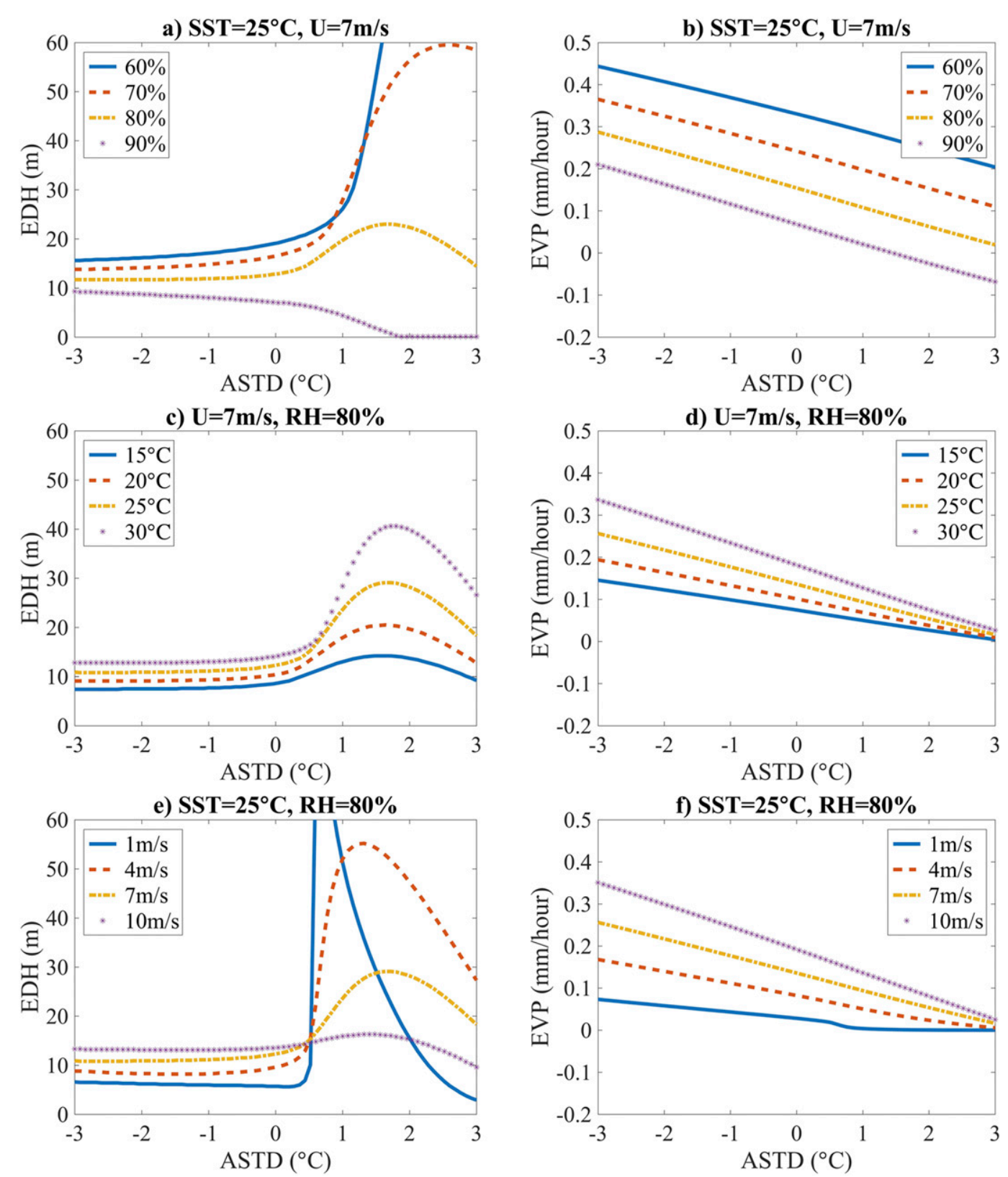

FIG. 1. Typical results from the sensitivity analysis of EDH and evaporation vs ASTD for various values of (a),

(b) relative humidity, (c),(d) SST, and (e),(f) wind speed.

The historical data of EDH and evaporation are estimated using the air-sea variables from the reanalysis products of the National Centers for Environmental Prediction (NCEP) Climate Forecast System Reanalysis (CFSR) dataset (with an hourly temporal resolution and a spatial resolution of $\left.0.312^{\circ} \times 0.312^{\circ}\right)($ Saha et al. 2010). This dataset covers a 32-yr period from 1979 to 2010, and so our analysis is also limited to this period. The reliability and suitability of the NCEP CFSR dataset for the evaporation duct and evaporation research have been discussed fully in several previously published works (Yang et al. 2009; Ramsaur 2009; McKeon 2013; Shi et al. 2015c; Zhang et al. 2016a; Yang et al. 2016).

The evaporation duct is prevalent in the marineatmospheric environment (Skolnik 1990), within which the northwestern Pacific Ocean and its marginal seas is a hot spot for evaporation duct research (Ramsaur 2009; Shi et al. 2015c; Yang et al. 2009; Zhao et al. 2013; McKeon 2013; Zhao et al. 2013). Hence, we also focus our study in this region. As shown in Fig. 2, we select 


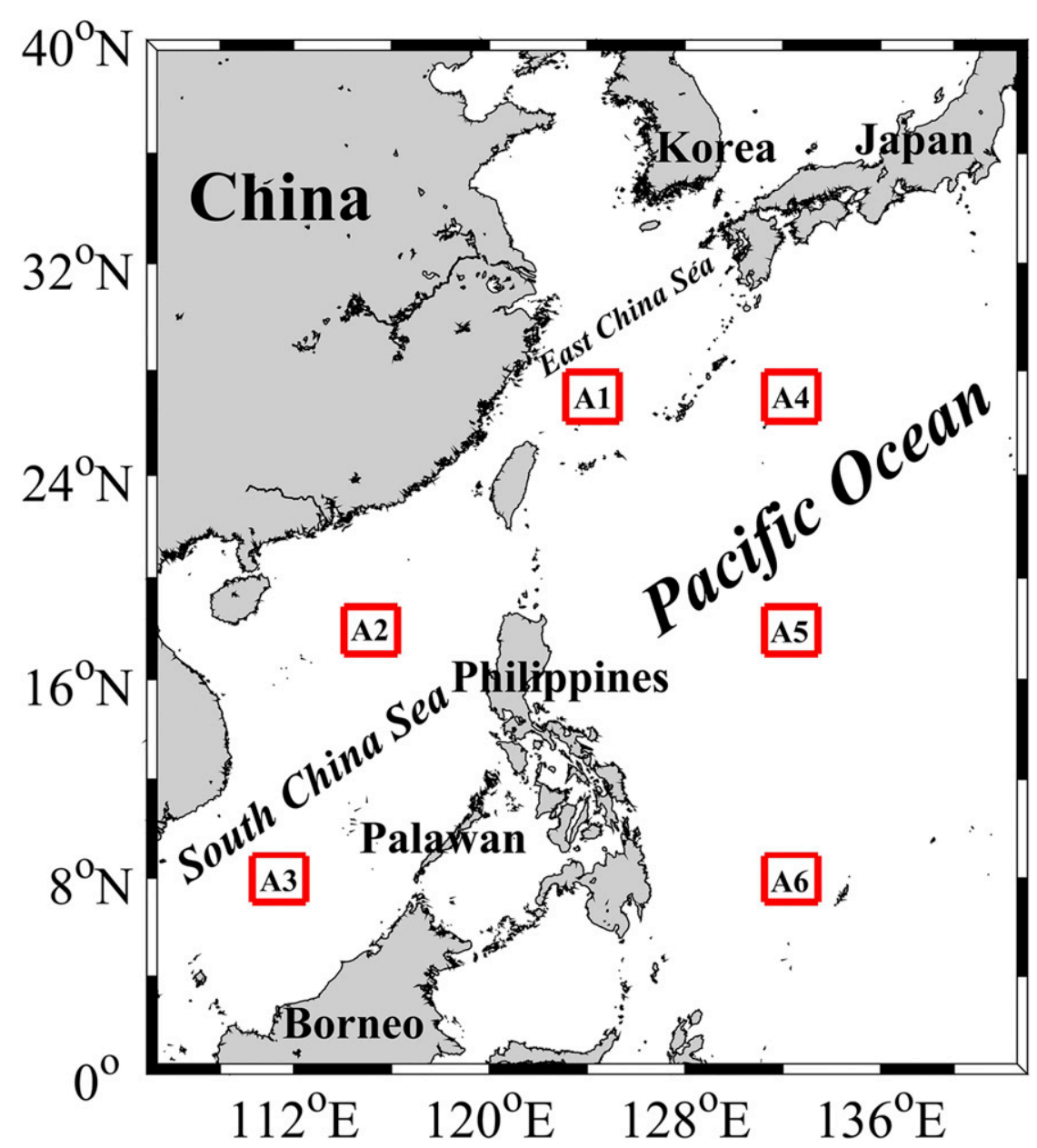

FIG. 2. Map of the northwestern Pacific Ocean and its marginal seas. The red rectangles indicate the focus areas marked A1 $\left(26^{\circ}-28^{\circ} \mathrm{N}, 123^{\circ}-125^{\circ} \mathrm{E}\right), \mathrm{A} 2\left(17^{\circ}-19^{\circ} \mathrm{N}, 114^{\circ}-116^{\circ} \mathrm{E}\right)$, A3 $\left(7^{\circ}-9^{\circ} \mathrm{N}, 110^{\circ}-112^{\circ} \mathrm{E}\right)$, A4 $\left(26^{\circ}-28^{\circ} \mathrm{N}, 131^{\circ}-133^{\circ} \mathrm{E}\right)$, A5 $\left(17^{\circ}-19^{\circ} \mathrm{N}, 131^{\circ}-133 \mathrm{E}\right)$, and A6 $\left(7^{\circ}-9^{\circ} \mathrm{N}, 131^{\circ}-133^{\circ} \mathrm{E}\right)$, in the East China Sea, the northern and southern regions of the South China Sea, and the northwestern Pacific Ocean.

study areas covering the northwestern Pacific Ocean and its main marginal seas with different longitudes and latitudes, including the East China Sea (A1: $26^{\circ}-28^{\circ} \mathrm{N}$, $\left.123^{\circ}-125^{\circ} \mathrm{E}\right)$, the northern region of the South China Sea $\left(\mathrm{A} 2: 17^{\circ}-19^{\circ} \mathrm{N}, 114^{\circ}-116^{\circ} \mathrm{E}\right)$, the southern region of the South China Sea $\left(\mathrm{A} 3: 7^{\circ}-9^{\circ} \mathrm{N}, 110^{\circ}-112^{\circ} \mathrm{E}\right)$, and three in the Pacific Ocean with the same longitude (A4: $26^{\circ}-28^{\circ} \mathrm{N}, 131^{\circ}-133^{\circ} \mathrm{E}$; A5: $17^{\circ}-19^{\circ} \mathrm{N}, 131^{\circ}-133^{\circ} \mathrm{E}$; and A6: $\left.7^{\circ}-9^{\circ} \mathrm{N}, 131^{\circ}-133^{\circ} \mathrm{E}\right)$. Each area encompassed in a red box includes 56 reanalysis grid points, and the time series of EDH and evaporation are then obtained by averaging over each research box.

From a preliminary analysis of the scatterplots of EDH and evaporation, we find that they generally follow a power-law relationship. Figure 3 a shows a good example illustrating this trend using data from study area A3. To make this clearer, we take the natural logarithm of the data and the trend in the transformed domain becomes linear (Fig. 3b). Consequently, we adopt the following formula to represent the power-law varying trend:

$$
\mathrm{EDH}=\alpha \mathrm{EVP}^{\beta}
$$

where $\alpha$ and $\beta$ are the coefficients to be determined, and EVP stands for evaporation.

Again, taking the natural logarithm of both sides of Eq. (4) transforms it into an equation where the logarithm of EDH is linearly related to the logarithm of evaporation. Linear regression analysis between the two natural logarithmic time series yields

$$
\ln (\mathrm{EDH})=\ln (\alpha)+\beta \ln (\mathrm{EVP}) .
$$



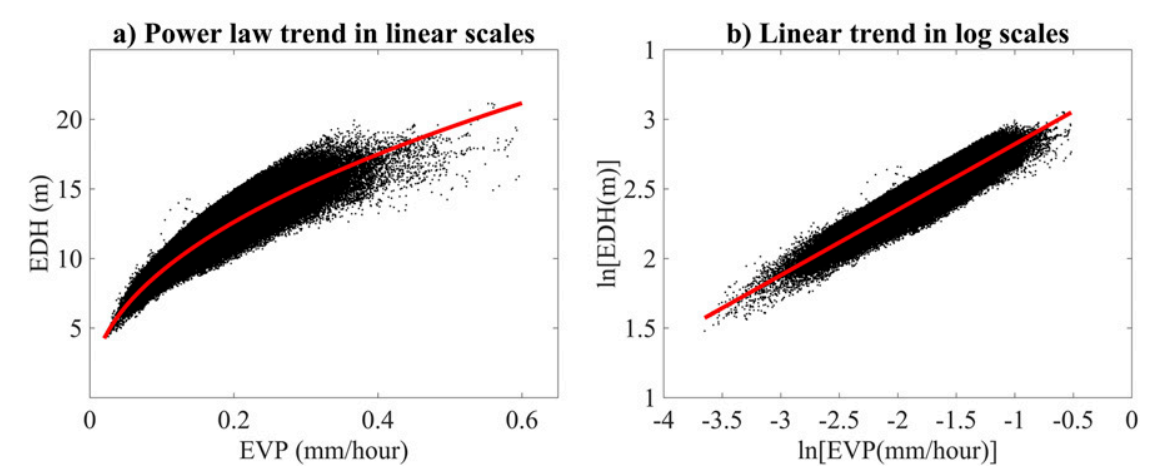

FIG. 3. Example scatterplots of EDH and EVP on (a) linear scales and (b) log scales. The data (black dots) are obtained from study area A3, as shown in Fig. 2. The best-fit linear regression in (b) and its original formation in log scales in (a) are indicated (red lines).

In the example shown in Figs. $3 \mathrm{a}$ and $3 \mathrm{~b}$, the red lines represent Eqs. (4) and (5) in linear scales and log scales, respectively. We find that these two equations are a good description of the general variation trend of EDH with evaporation.

Statistically speaking, Figs. $3 \mathrm{a}$ and $3 \mathrm{~b}$ show that the relationship between EDH and evaporation also exhibits a characteristic of temporal clustering. This clustering is natural, caused by both EDH and evaporation temporally fluctuating within a specific range, and thus we need to consider this in our analysis. Accordingly, we propose a three-parameter empirical model, below, by adding a stochastic item to Eq. (4),

$$
\mathrm{EDH}=\alpha \mathrm{EVP}^{\beta} e^{\varepsilon},
$$

where $\alpha, \beta, \mathrm{EVP}$, and EDH are the same as described above. The $e^{\varepsilon}$ is the stochastic factor. The term $\varepsilon$ has a zero-mean value and variances are indicated by $\sigma^{2}$.

Models with similar forms as Eq. (6) have been widely used to model the errors of processes and phenomena in many other fields, such as the hydrological cycle (Hossain and Anagnostou 2006; Villarini et al. 2009; Tian et al. 2013) and oceanic sound attenuation (Duan et al. 2016). However, to the best of our knowledge, this is the first attempt to adopt this kind of model for studying evaporation duct and evaporation. We process the variables in Eq. (6) using natural logarithm transformation and then obtain

$$
\ln (\mathrm{EDH})=\ln (\alpha)+\beta \ln (\mathrm{EVP})+\varepsilon,
$$

which is a linear regression expression, and we can estimate the relevant parameters using the least squares method. The $\varepsilon$ is assumed to be normally distributed, which is reasonable and acceptable (Jaynes 1957; Graybill 1976). In following discussion, our analysis is carried out in the transformed domain.
The NCEP CFSR dataset covers a time span of 32 years, from 1 January 1979 to 31 December 2010. We used the first 22 years as the calibration period to fit the model [Eq. (7)], and the fitted model parameters for different focus areas are shown in Table 1 . To test the model, we used the remaining data of 2001-10. These data are not used in the parameter estimation process. The scatterplots for the real temporal clustering, with the linear regression fitted with the historical data, are shown in Figs. 4a, 4d, 4g, 4j, 4m, and 4p. We used the three-parameter empirical model to generate the predicted clustering, and the obtained scatterplots are shown in Figs. 4b, 4e, 4h, 4k, 4n, and 4q. Furthermore, the probability density functions (PDFs) of real and predicted data are compared as shown in Figs. 4c, 4f, 4i, $41,4 \mathrm{o}$, and 4r. Apparently, the similarities in the scatterplots and PDFs between predicted and actual data verify the excellent capability of our proposed model in estimating the temporal clustering.

\section{Discussion and concluding remarks}

The major contribution of our work reported in this paper is a statistical analysis of the relationship between

TABLE 1. Fitted parameters of the proposed empirical models in the different study areas using data during 1979-2000.

\begin{tabular}{cccc}
\hline \hline Area No. ${ }^{a}$ & $\alpha$ & $\beta$ & $\sigma$ \\
\hline A1 & 17.2377 & 0.3275 & 0.1468 \\
A2 & 23.2057 & 0.4074 & 0.0884 \\
A3 & 26.9208 & 0.4713 & 0.0768 \\
A4 & 18.7952 & 0.3338 & 0.1126 \\
A5 & 24.1431 & 0.4115 & 0.0786 \\
A6 & 27.7462 & 0.4961 & 0.0760 \\
\hline
\end{tabular}

${ }^{\mathrm{a}} \mathrm{A} 1\left(26^{\circ}-28^{\circ} \mathrm{N}, 123^{\circ}-125^{\circ} \mathrm{E}\right), \mathrm{A} 2\left(17^{\circ}-19^{\circ} \mathrm{N}, 114^{\circ}-116^{\circ} \mathrm{E}\right), \mathrm{A} 3\left(7^{\circ}-9^{\circ} \mathrm{N}\right.$, $\left.110^{\circ}-112^{\circ} \mathrm{E}\right), \mathrm{A} 4\left(26^{\circ}-28^{\circ} \mathrm{N}, 131^{\circ}-133^{\circ} \mathrm{E}\right), \mathrm{A} 5\left(17^{\circ}-19^{\circ} \mathrm{N}, 131^{\circ}-133^{\circ} \mathrm{E}\right)$, and $\mathrm{A} 6\left(7^{\circ}-9^{\circ} \mathrm{N}, 131^{\circ}-133^{\circ} \mathrm{E}\right)$. 


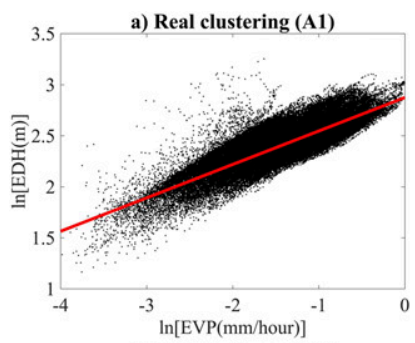

d) Real clustering (A2)
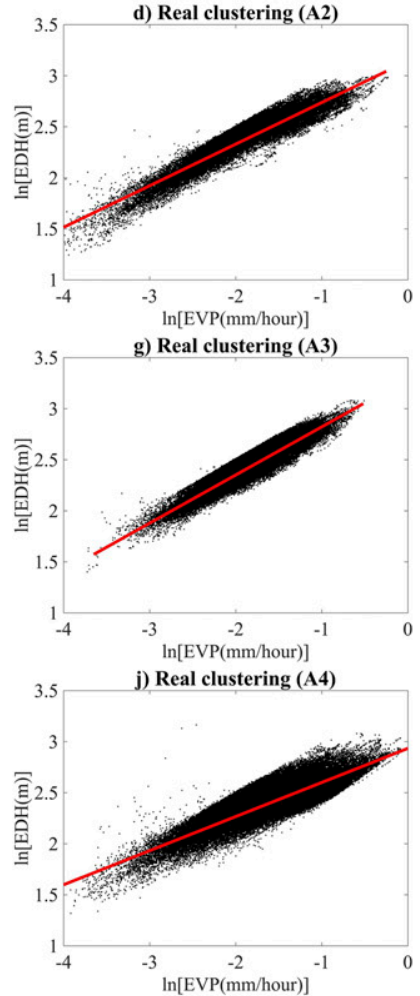

m) Real clustering (A5)

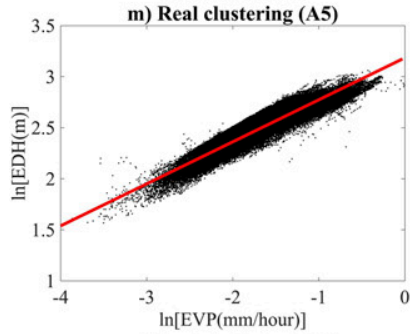

p) Real clustering (A6)

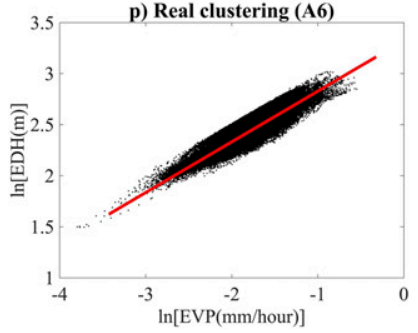

b) Predicted clustering (A1)

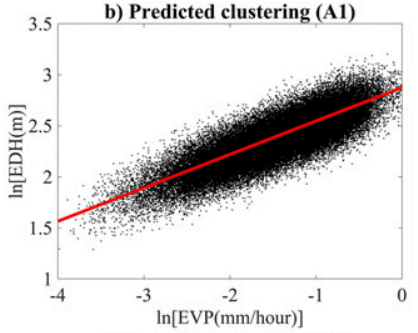

e) Predicted clustering (A2)
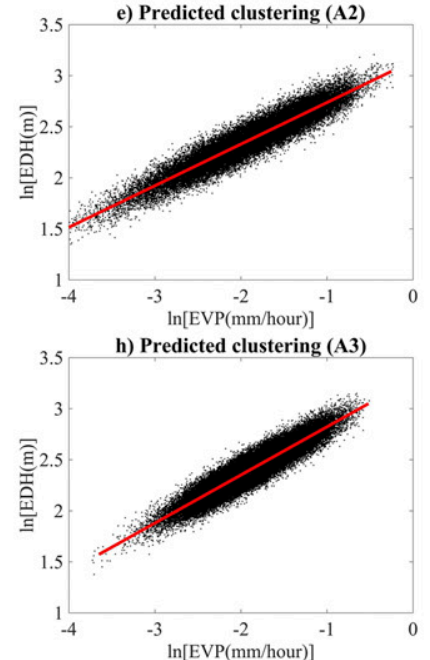

k) Predicted clustering (A4)

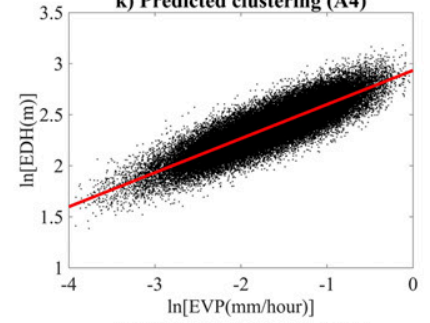

n) Predicted clustering (A5)

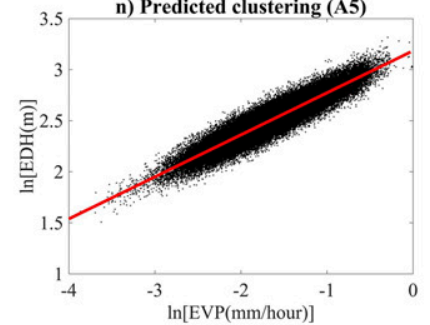

q) Predicted clustering (A6)

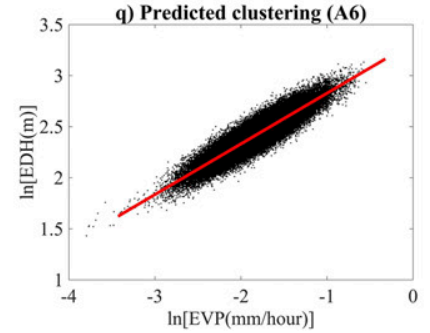

c) PDF comparison (A1)

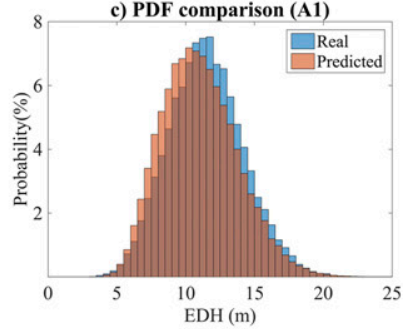

f) PDF comparison (A2)

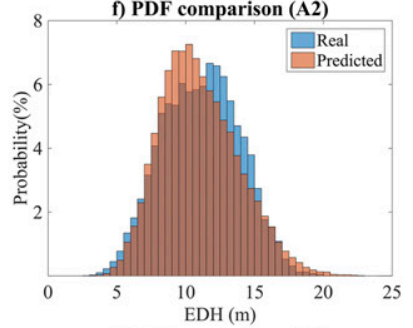

i) PDF comparison (A3)
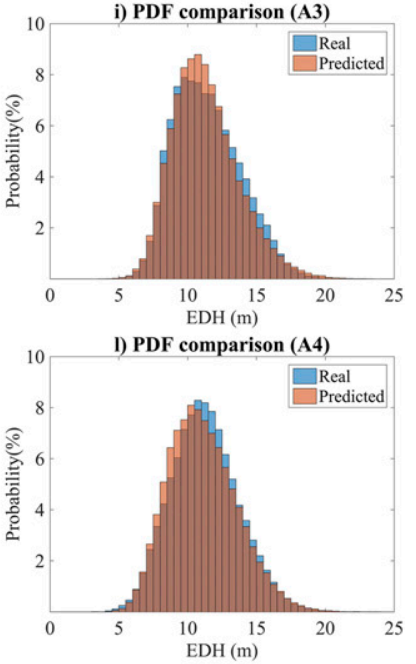

o) PDF comparison (A5)

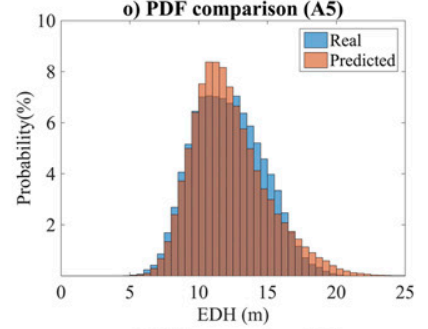

r) PDF comparison (A6)

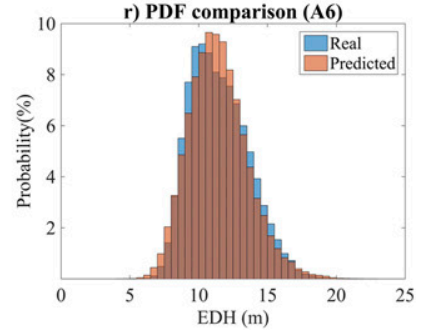

FIG. 4. Evaluation of the three-parameter empirical model to estimate the temporal clustering characteristics. The notations A1-A6 stand for the study areas shown in Fig. 2. Scatterplots of (left) real clustering and (middle) predicted clustering, and (right) comparisons of the PDFs between the real distribution and the predicted distribution by the proposed model. The linear regression fitting from the historical data is shown by the thick red line. 
the evaporation duct and evaporation. To our best knowledge, this is the first attempt to carry out such a study.

We find that under unstable conditions ( ASTD $<0^{\circ} \mathrm{C}$ ), there is a strong correlation between EDH and evaporation, whereas under a stable condition the relationship is less relevant (Fig. 1). We also calculate the probability of occurrence of an unstable atmospheric condition at all sites (A1-A6), and the results are 74\%, 77\%, 86\%, 75\%, $93 \%$, and $97 \%$, respectively. It can be seen that unstable conditions prevail over the open sea. Therefore, our research with respect to such conditions is also of considerable practical importance.

Besides the hydrolapse link, the formation of the evaporation duct is also associated with temperature inversion, albeit relatively infrequently (Turton et al. 1988; Lentini 2015). When warm air covers colder water, the inversion layer suppresses the activities of turbulence, causing the accumulation of moist air and, subsequently, an inversion-induced evaporation duct. This is also obtainable from our sensitivity analysis. As shown in Fig. 1, when the ASTD is positive and keeps increasing, evaporation decreases steadily. By contrast, the evaporation duct reacts abnormally. This is mainly because, when ASTD $>0{ }^{\circ} \mathrm{C}$, evaporation contributes less to the evaporation duct, and temperature inversion plays an increasing role in the formation.

Then we explore the empirical relationship between the evaporation duct and evaporation based on a dataset from 1979 to 2010 over different regions covering the northwestern Pacific Ocean, the South China Sea, and the East China Sea, where the evaporation duct is prevalent (Yang et al. 2009; Zhao et al. 2013). We find that the power-law trend between the evaporation duct and evaporation emerging from this analysis is a general one that applies to all the research areas. The proposed three-parameter empirical model is also suitable at all sites.

The correlation of the quantified relationships on the geophysical parameters- that is, latitude and longitudecan be observed in the spatial variations of the parameters $(\alpha, \beta$, and $\sigma)$ from model fitting. Among the six focus areas, A1-A3 are located at the same latitudes as A4-A6, respectively, and A4-A6 share the same longitude. A1-A3 and $\mathrm{A} 4-\mathrm{A} 6$ are equally distributed in latitude. When comparing the slopes of the models fitted from A1-A3 and A4-6, the values of $\beta$ [the slope in Eq. (7)] shows an obvious increasing trend from north to south (seen in Fig. 5). This means that for the same increase in evaporation, a higher EDH is observed from north to south. But the difference between A1 and A4, A2 and $\mathrm{A} 5$, and $\mathrm{A} 3$ and $\mathrm{A} 6$ is much smaller and the fitted lines are much closer to each other. Therefore, among the

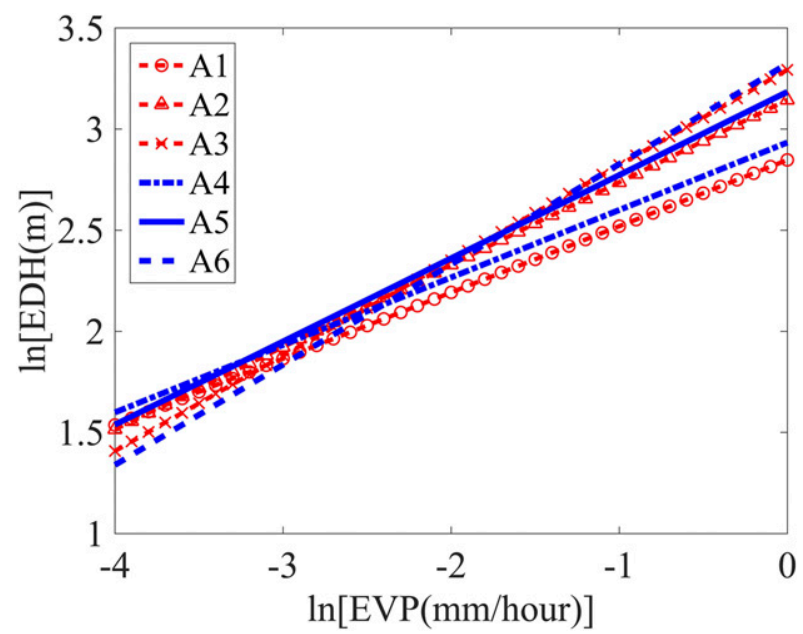

FIG. 5. Comparison of the slopes of best-fit linear regression shown in Fig. 4. The study areas sharing the same longitudinal location are plotted in the same color [A1-A3 (red); A4-A6 (blue)].

geographic distribution factors, latitude is the key player, with longitude having a weaker influence.

The geographical influence is also reflected in the value of $\sigma$, which indicates the dispersion of the temporal clustering effect. From Fig. 4 and Table 1, we can see that farther to the south, a smaller dispersion corresponds to a smaller $\sigma$; and a small dispersion means less fluctuation in evaporation ducts and evaporation. Compared with the sites of equal latitude, sites A1-A3 have larger $\sigma$ than A4-A6, respectively. This may derive from the influence of the nearby coast (Zhu and Atkinson 2005; Atkinson and Zhu 2006).

It is also worth noting that our focus areas are mainly located in the northwestern Pacific Ocean and its marginal seas. Several previous studies have shown that the Mediterranean Sea (Magaldi et al. 2016; Gürbüz 2016) and the Arabian Sea (Pasricha et al. 2002; Zhang et al. 2016a) are also hot spots for evaporation ducts. We plan to extend the present study to these areas in future work.

Acknowledgments. The authors thank the National Center for Atmospheric Research for providing the reanalysis datasets used in this paper. All the reanalysis data can be obtained through NCAR (https://rda.ucar.edu/). Thanks also to three anonymous reviewers for their valuable comments, which helped to improve the manuscript.

\section{REFERENCES}

Atkinson, B., and M. Zhu, 2006: Coastal effects on radar propagation in atmospheric ducting conditions. Meteor. Appl., 13, 53-62, https://doi.org/10.1017/S1350482705001970. 
Babin, S. M., and G. D. Dockery, 2002: LKB-based evaporation duct model comparison with buoy data. J. Appl. Meteor., 41, 434-446, https://doi.org/10.1175/1520-0450(2002)041<0434: LBEDMC $>2.0 . C O ; 2$.

Bean, B. R., and E. J. Dutton, 1966: Radio Meteorology. National Bureau of Standards Monogr., No. 92, U.S. Government Printing Office, 435 pp., https://doi.org/ 10.6028/nbs.mono.92.

Brooks, I. M., 2001: Air-sea interaction and spatial variability of the surface evaporation duct in a coastal environment. Geophys. Res. Lett., 28, 2009-2012, https://doi.org/10.1029/ 2000GL012751.

Duan, R., K. D. Yang, Y. L. Ma, and N. R. Chapman, 2016: A simple expression for sound attenuation due to surface duct energy leakage in low-latitude oceans. J. Acoust. Soc. Amer., 139, E118, https://doi.org/10.1121/1.4947012.

Fairall, C. W., E. F. Bradley, D. P. Rogers, J. B. Edson, and G. S. Young, 1996: Bulk parameterization of air-sea fluxes for tropical ocean-global atmosphere coupled-ocean atmosphere response experiment. J. Geophys. Res., 101, 3747-3764, https:// doi.org/10.1029/95JC03205.

$\longrightarrow,-$ _ J. E. Hare, A. A. Grachev, and J. B. Edson, 2003: Bulk parameterization of air-sea fluxes: Updates and verification for the COARE algorithm. J. Climate, 16, 571-591, https://doi.org/ 10.1175/1520-0442(2003)016<0571:BPOASF > 2.0.CO;2.

Fountoulakis, V., and C. Earls, 2016: Inverting for maritime environments using proper orthogonal bases from sparsely sampled electromagnetic propagation data. IEEE Trans. Geosci. Remote Sens., 54, 7166-7176, https://doi.org/10.1109/ TGRS.2016.2597138.

Frederickson, P., K. Davidson, and A. Goroch, 2000: Operational bulk evaporation duct model for MORIAH, version 1.2. Naval Postgraduate School, $70 \mathrm{pp}$.

Graybill, F. A., 1976: Theory and Application of the Linear Model. Duxbury Press, 704 pp.

Gürbüz, S. C., 2016: Assessing evaporation duct variability in the eastern Mediterranean Sea in support of radar and radio communications. M.S. thesis, Dept. of Meteorology, Naval Postgraduate School, 101 pp.

Hossain, F., and E. N. Anagnostou, 2006: A two-dimensional satellite rainfall error model. IEEE Trans. Geosci. Remote Sens., 44, 1511-1522, https://doi.org/10.1109/TGRS.2005.863866.

Jaynes, E. T., 1957: Information theory and statistical mechanics. Phys. Rev., 106, 620-630, https://doi.org/10.1103/ PhysRev.106.620.

Kang, D., and Q. Wang, 2016: Optimized estimation of surface layer characteristics from profiling measurements. Atmosphere, 7, 14, https://doi.org/10.3390/atmos7020014.

Lentini, N. E., 2015: A numerical study investigating sensitivity of radar wave propagation to the marine atmospheric boundary layer environment. M.S. thesis, School of Coastal and Marine Systems Science, Coastal Carolina University, 115 pp.

—, and E. E. Hackett, 2015: Global sensitivity of parabolic equation radar wave propagation simulation to sea state and atmospheric refractivity structure. Radio Sci., 50, 1027-1049, https://doi.org/10.1002/2015RS005742.

Liu, W. T., K. B. Katsaros, and J. A. Businger, 1979: Bulk parameterization of air-sea exchanges of heat and water vapor including the molecular constraints at the interface. J. Atmos. Sci., 36, 1722-1735, https://doi.org/10.1175/ 1520-0469(1979)036<1722:BPOASE > 2.0.CO;2.

Magaldi, A. V., M. Mateu, J. Bech, and J. Lorente, 2016: A long term (1999-2008) study of radar anomalous propagation conditions in the Western Mediterranean. Atmos. Res., 169, 73-85, https://doi.org/10.1016/j.atmosres.2015.09.027.

McKeon, B. D., 2013: Climate analysis of evaporation ducts in the South China Sea. M.S. thesis, Dept. of Meteorology, Naval Postgraduate School, $111 \mathrm{pp}$.

Pasricha, P., M. Prasad, and S. Sarkar, 2002: Comparison of evaporation duct models to compute duct height over Arabian Sea and Bay of Bengal. Indian J. Radio Space Phys., 31, 155-158.

Ramsaur, D. C., 2009: Climate analysis and long range forecasting of radar performance in the western North Pacific. M.S. thesis, Dept. of Meteorology, Naval Postgraduate School, 115 pp.

Saeger, J. T., N. G. Grimes, H. E. Rickard, and E. E. Hackett, 2015: Evaluation of simplified evaporation duct refractivity models for inversion problems. Radio Sci., 50, 1110-1130, https://doi.org/10.1002/2014RS005642.

Saha, S., and Coauthors, 2010: The NCEP Climate Forecast System Reanalysis. Bull. Amer. Meteor. Soc., 91, 1015-1057, https:// doi.org/10.1175/2010BAMS3001.1.

Shi, Y., K. Yang, Y. Yang, and Y. Ma, 2015a: Experimental verification of effect of horizontal inhomogeneity of evaporation duct on electromagnetic wave propagation. Chin. Phys., 24B, 044102, doi:10.1088/1674-1056/24/4/044102.

$-, \ldots, \ldots$, and,$- 2015 \mathrm{~b}$ : Influence of obstacle on electromagnetic wave propagation in evaporation duct with experiment verification. Chin. Phys., 24B, 054101, https:// doi.org/10.1088/1674-1056/24/5/054101.

,,--- , and $\longrightarrow, 2015 \mathrm{c}$ : A new evaporation duct climatology over the South China Sea. J. Meteor. Res., 29, 764-778, https://doi.org/10.1007/s13351-015-4127-6.

Skolnik, M. I., 1990: Radar Handbook. 2nd ed. McGraw-Hill, 1163 pp.

$\mathrm{Su}, \mathrm{T}$., T. Feng, and G. Feng, 2015: Evaporation variability under climate warming in five reanalyses and its association with pan evaporation over China. J. Geophys. Res. Atmos., 120, 8080-8098, doi:10.1002/2014JD023040.

Tian, Y., G. J. Huffman, R. F. Adler, L. Tang, M. Sapiano, V. Maggioni, and H. Wu, 2013: Modeling errors in daily precipitation measurements: Additive or multiplicative? Geophys. Res. Lett., 40, 2060-2065, https://doi.org/10.1002/ grl.50320.

Turton, J., D. Bennetts, and S. Farmer, 1988: An introduction to radio ducting. Meteor. Mag., 117, 245-254.

Villarini, G., W. F. Krajewski, G. J. Ciach, and D. L. Zimmerman, 2009: Product-error-driven generator of probable rainfall conditioned on WSR-88D precipitation estimates. Water Resour. Res., 45, 58-69, https://doi.org/10.1029/2008WR006946.

Wagner, M., P. Gerstoft, and T. Rogers, 2016: Estimating refractivity from propagation loss in turbulent media. Radio Sci., 51, 1876-1894, https://doi.org/10.1002/2016RS006061.

Yang, K., Y. Ma, and Y. Shi, 2009: Spatio-temporal distributions of evaporation duct for the West Pacific Ocean. Acta Phys. Sin., 58, 7339-7350.

— , Q. Zhang, Y. Shi, Z. He, B. Lei, and Y. Han, 2016: On analyzing space-time distribution of evaporation duct height over the global ocean. Acta Oceanol. Sin., 35 (7), 20-29, https://doi.org/10.1007/s13131-016-0903-0.

,$- \ldots$, and,$- 2017 \mathrm{a}$ : Interannual variability of the evaporation duct over the South China Sea and its relations with regional evaporation. J. Geophys. Res. Oceans, 122, 6698-6713, doi:10.1002/2017JC012683.

Yang, S., X. Li, C. Wu, X. He, and Y. Zhong, 2017b: Application of the PJ and NPS evaporation duct models over the South China 
Sea (SCS) in winter. PLoS One, 12, e0172284, https://doi.org/ 10.1371/journal.pone.0172284.

Yardim, C., P. Gerstoft, and W. S. Hodgkiss, 2006: Estimation of radio refractivity from radar clutter using Bayesian Monte Carlo analysis. IEEE Trans. Antennas Propag., 54, 1318-1327, https://doi.org/10.1109/TAP.2006.872673.

$\mathrm{Yu}, \mathrm{L} ., 2007$ : Global variations in oceanic evaporation (1958-2005): The role of the changing wind speed. J. Climate, 20, 5376-5390, https://doi.org/10.1175/2007JCLI1714.1.

— , and R. A. Weller, 2007: Objectively analyzed air-sea heat fluxes for the global ice-free oceans (1981-2005). Bull. Amer. Meteor. Soc., 88, 527-539, https://doi.org/10.1175/BAMS-88-4-527.

, X. Jin, and R. A. Weller, 2008: Multidecade global flux datasets from the Objectively Analyzed Air-Sea Fluxes (OAFlux) project: Latent and sensible heat fluxes, ocean evaporation, and related surface meteorological variables. Woods Hole Oceanographic Institution OAFlux Project Tech. Rep. OA-2008-01, 64 pp.
Zhang, Q., K. Yang, and Y. Shi, 2016a: Spatial and temporal variability of the evaporation duct in the Gulf of Aden. Tellus, 68A, 29792, doi:10.3402/tellusa.v68.29792.

,,--- , and X. Yan, 2016b: Oceanic propagation measurement in the Northern part of the South China Sea. Oceans 2016-Shanghai, Shanghai, China, IEEE Oceanic Engineering Society, 4 pp., doi:10.1109/OCEANSAP.2016.7485350.

Zhao, X. F., D. X. Wang, S. X. Huang, K. Huang, and J. Chen, 2013: Statistical estimations of atmospheric duct over the South China Sea and the tropical eastern Indian Ocean. Sci. Bull., 58, 2794-2797, https://doi.org/10.1007/s11434-013-5942-8.

Zhu, M., and B. W. Atkinson, 2005: Simulated climatology of atmospheric ducts over the Persian Gulf. Bound.-Layer Meteor., 115, 433-452, https://doi.org/10.1007/s10546-004-1428-1.

Zveryaev, I. I., and A. A. Hannachi, 2012: Interannual variability of Mediterranean evaporation and its relation to regional climate. Climate Dyn., 38, 495-512, https://doi.org/10.1007/ s00382-011-1218-7. 